\title{
GC-MS Evaluation of Essential Oil Constituents from Rosa Damascena Wild Rose: Effect of Season and Climatic Conditions
}

\author{
Rumana Saeed ${ }^{1}$, Saima Gul ${ }^{1}$, Murad Ali Khan ${ }^{1 *}$, Mohammad Afzal Kamboh, ${ }^{2}$ \\ Muhammad Iqbal Khan ${ }^{1}$ and S.T.H. Sherazi ${ }^{3}$ \\ ${ }^{1}$ Department of Chemistry, Kohat University of Science \& Technology, Kohat 26000, Pakistan \\ ${ }^{2}$ Department of Chemistry, Shaheed Benazir Bhutto University, Shaheed Banazir Nawab Shah. \\ ${ }^{3}$ National Center of Excellence in Analytical Chemistry, University of Sindh, Jamshoro 76080, Pakistan \\ *Corresponding Author Email: drmalikhan@yahoo.com \\ Received 10 October 2017, Revised 30 November 2017, Accepted 01 December 2017
}

\begin{abstract}
The present study describes the extraction and identification of essential oil constituents from Rosa damascena wild rose as well as effect of season and climatic conditions of selected regions (KPK, Pakistan). Essential oil constituents were extracted using Steam distillation (SD) method, whereas the analysis of the extracted components were carried out using GC coupled with MS. A total of seven oil components namely; o-cymene, d-limonene, (R)-(+)-citronellal, $n$-heneicosane, eugenol methyl ether, p-menth-1-en-8-ol and eucalyptol were extracted and quantified. GC-MS analysis indicated that the Rosa Damascena Mill contains several important volatile constituents i.e. (R)(+)-citronellal, o-cymene, d-limonene, eucalyptol, p-menth-1-en-8-ol, eugenol methyl ether and nheneicosane with extraction yield $3.8 \%$ to $91.9 \%$. Seasonal effect investigation indicated that spring season showed high essential oil yield as compare to summer and winter. The chemical composition of volatile components analyzed in the essential oil, extracted from rose petals collected from Bannu and Peshawar in spring indicates high concentration of all components in Bannu petals as compared to Peshawar. Present research indicated that the geographical distribution and seasonal variation highly affect the essential oil constituents in Rosa damascena wild rose.
\end{abstract}

Keywords: Rosa damascena, Essential oil, Steam distillation, GC-MS.

\section{Introduction}

Plants with aromatic properties are traditionally used as remedies for human disease due to presence of valuable chemical composition. Recently, herbals product and their derivatives become attractive as clinical drugs [1]. Rose family contains wide range of aromatic plants that can be used as clinical approach. Rosaceae is a large subcosmopolitan family includes 100 genera; one of these genera is Rosa that includes 100-150 species. It is divided into four subgenera i.e., Hulthemia, Platyrhodon, Hesperhodos and Eurosa [2, 3]. Among these subgenera, three have few species and subgenus Eurosa (Rosa) is further divided into
10 sections. The sections Caninae and Cinnamomeae are the largest and comprise about 50 and 80 species, respectively [4]. About 25 species of Rosa are wild in nature and from these wild species of Rosa larger number of cultivars are formed by asexual and vegetative reproduction; so more than 18000 cultivars are present $[5,6]$. These species are mainly located in temperate and warm areas of northern hemisphere [7]. For rose production, excess of sunlight, humid and moderate temperature is required, so optimum temperature range for roses is $15-25^{\circ} \mathrm{C}$, relative humidity $55-80 \%$ and 5-8 hours sunlight [8,9]. 
Roses are growing wildly as an ornate plant and cherished for their fragrance as well as for their beauty $[10,11]$. Apart from its use for ornamental purpose they also show pharmacological (antidepressant, digestive, antiseptic, antioxidant, antiviral, antispasmodic and relaxant) properties [12-14].

Rose products (rose water, gulqand, oil) are in high demand all over the world. Especially essential oil is most important part of rose plant being used. Among the huge variety of rose species $R$. damascene Mill., $R$. gallica $L ., R$. moshata Herrm and $R$. centifolia $L$, by virtue of their illustrious as well as attractive fragrance, possesses paramount importance in essential oil production [10,11]. Consequently, these species are responsible for the production of essential oil on larger scale in many countries. According to the recently made survey Turkey and Bulgaria appeared as the largest rose oil producers in the world. Literature analysis reveals that the per annum essential oil production in Turkey is estimated to be 1.2-1.8 tonnes from 6000 to 8000 tonnes of roses [13].

In spite of these facts the precise extraction and determination of essential rose oil is the main ambition of the modern era. Essential oils are widely applied in the perfume and cosmetic industries as well as they are extensively important in food chemistry to pharmaceutics [15]. Essential oil and their derivatives contain complex mixture that can be divided into hundred of individual chemical compounds [16]. Numerous thousand volatile compounds have been identified from various rose species. Most of these compounds are terpenes, esters, alcohols, aldehydes and ketones or alkanes [17]. Several researchers have paid strenuous efforts for the extraction of essential oil from roses. Consequently, they adopted different techniques like $\mathrm{CO}_{2}$ extraction, steam or hydro distillation, solvent extraction and solid-phase trapping-solvent extraction for extraction of odorous/volatile components from wild roses [18]. Recently extracted essential oil from $R$. damascene Mill by superheated water extraction using twodimensional GC with TOF mass spectrometric technique [19] have been reported. Above mentioned techniques are laborious, tedious as well as time consuming. Despite these facts, each individual method has its own limitation such as, In Solid-phase trapping-solvent extraction selection of adsorbent is basic problem because of their/adsorbent's selectivity towards specific organic compounds and solvent extraction technique is suitable only for those samples which do not contain lipids molecules [17]. Thus, among the above mentioned techniques the most frequently used technique is steam distillation due to its simple procedure that yields approximately $93 \%$ of the essential oil [20].

Analysis of extracted oil by GC using FID, MS or GC-olfactometry have been performed successfully. Gas chromatography coupled with Mass detection is considered to be a powerful tool for separation and identification of volatile organic constituents. Capillary column in GC offers remarkable separation power while mass spectral libraries in MS eliminate need of standards which are necessary when using GC with other detection techniques like FID, ECD etc. Due to volatility and low UV absorptive property of different odorous/volatile components in rose oil GC-MS is preferred over HPLC. Recently, extraction technique i.e., supercritical fluid extraction (SFE) and solid phase microextraction (SPME) coupled with above detectors are used for essential Oil purpose [21], But, time consuming and low sensitivity are main issues. In fact, GC-MS is the best and useful method for the Essential Oil determination and quantification due to its simplicity, rapidity and efficiency [22-25]. Also, GC-MS with fingerprint criteria have been shown reliable information for the essential Oil components that will be useful for medicine aspects [20].

\section{Materials and Method \\ Chemical and reagents}

Dichloromethane (DCM) was purchased from Sci-Tech (Sigma-Aldrich Labor Chemikalien).

\section{Plant material}

Rose flowers were collected from three different regions (Peshawar, Bannu and Chitral) of 
Khyber Pakhtunkhwa (KPK), Pakistan. The petals and sepals of the flowers were separated and the unwanted material like anthers and pollens were removed. The raw material (petals and sepals) was dry under shade (for a day only) at room temperature in order to remove extra moisture. Both petals and sepals were weighed before and after drying (until the value become constant or stable).

\section{Local climate}

The climatic condition of selected KPK regions is shown below. The duration and average highest and lowest seasonal temperature of each region is given in (Table 1). (Pakistan Meteorological Department, 2013-2014).

Table-1. Regional climatic conditions of KPK, Pakistan.

\begin{tabular}{llcc}
\hline S.No & Region & Temperature $\left({ }^{\circ} \mathbf{C}\right)$ \\
\hline & & Summer \\
1 & Peshawar & $42-43$ \\
2 & Bannu & $36-38$ \\
3 & Chitral & $18-22$ \\
\hline \multicolumn{3}{l}{ Winter } \\
2 & Peshawar & $18-20$ \\
3 & Bannu & $08-14$ \\
\hline \multirow{2}{*}{1} & Phitral & $0-5$ \\
2 & Bannu & Spring & $22-29$ \\
3 & Chitral & & $14-20$ \\
\hline
\end{tabular}

\section{Sample preparation and essential oil extraction}

Oil extraction was carried through soxlet extraction method. Briefly, fresh dried petals and sepals form rose flowers were randomly selected and divided in 3 groups then washed and dried (drying of samples were carried out under shade). The proposed samples were mortared, sieved and stored in (Refrigerator) until analysis. The steam distillation technique was used for extraction of essential oil composition from flowers according to dried, plant material was placed in the plant chamber of the still and the steam was allowed to pass through the material under pressure which softens the cells and allows the Essential Oil to escape in vapor form. The temperature of the steam must be high enough to vaporize the oil present, yet not so high that it destroys the plants or burns the Essential Oils. Besides the steam tiny droplets of Essential Oil evaporates and travel through a tube into the still's condensation chamber. Here Essential Oil vapors condense with the steam. The essential oil forms droplets on the surface of the water. To separate the Essential Oil from the water, the droplets are then decanted or skimmed off the top. The remaining water, a byproduct of distillation, is called floral water, distillate, or hydrosol.). 100 grams of powder (petals and sepals) from each group was weighed exactly and pureed into the distillation round bottom flask $(1000 \mathrm{~mL})$ separately. Thereafter, 500 $\mathrm{mL}$ water (Distilled water) was added and then set the distillation vessels followed by heating (at $100^{\circ} \mathrm{C}$ and each portion of sample was allowed to stand for $30 \mathrm{~min}$ at least in order to extracted oil completely). Then, the distilled water and extracted oils (two phase) were collected from up-side of round flask and moved into the separation funnel, up layer is oil and down layer is water then water removed carefully and oils were collected. The obtained oil was dehydrated using DCM (6-8 mL) and then kept in refrigerator $4^{\circ} \mathrm{C}$ for further analysis.

\section{Gas chromatography-mass spectrometer analysis}

The GC-MS analysis was carried out on a Shimatzu Japan (GC-MS QP 2010 plus) GCMS spectrometer. The column used was a capillary column DB- 5MS (length $30 \mathrm{~m}$, ID $0.25 \mathrm{~mm}$ and film $0.25 \mu \mathrm{m}$ ). The temperature programming was as follow; initial temperature $40^{\circ} \mathrm{C}$ (hold for less than $1 \mathrm{~min}$ ) then temperature increased gradually $\left(2^{\circ} \mathrm{C} / \mathrm{min}\right)$ to $90{ }^{\circ} \mathrm{C}$ and was further increased gradually $\left(3^{\circ} \mathrm{C} / \mathrm{min}\right)$ to $240^{\circ} \mathrm{C}$, held for $5 \mathrm{~min}$. The helium gas with purity $99.9999 \%$ was used as carrier gas with flow rate $1.27 \mathrm{~mL} \mathrm{~min}^{-1}$. Injection port temperature was set at $240^{\circ} \mathrm{C}$ and injection mode \ was split with split ratio 10:1. Temperature for mass analyzer (ion source) was set at $240^{\circ} \mathrm{C}$. The dehydrated oils were diluted by DCM and 1 $\mu \mathrm{L}$ was injected into the GC-MS. The analytes were analyzed in scan ion mode (SIM) with wide range of molecular weight $(60 \mathrm{~m} / \mathrm{z}$ to $600 \mathrm{~m} / \mathrm{z})$. 
The proposed essential oil compositions have been carried out both quantitative and qualitatively. Quantitative analysis of oil compositions were calculated based on peak area of spectra. The obtained oils were identified by matching the obtained mass signals (spectra) with the standard mass spectra library in the GC-MS software. The retention time of the obtained compounds was confirmed by some of the normal alkanes that have been considered in published literatures [11, 13, 18, 26, 27].

\section{Results and Discussion GC-MS analysis}

In order to identify the volatile compounds the aliquots amount of extracted wild rose essential
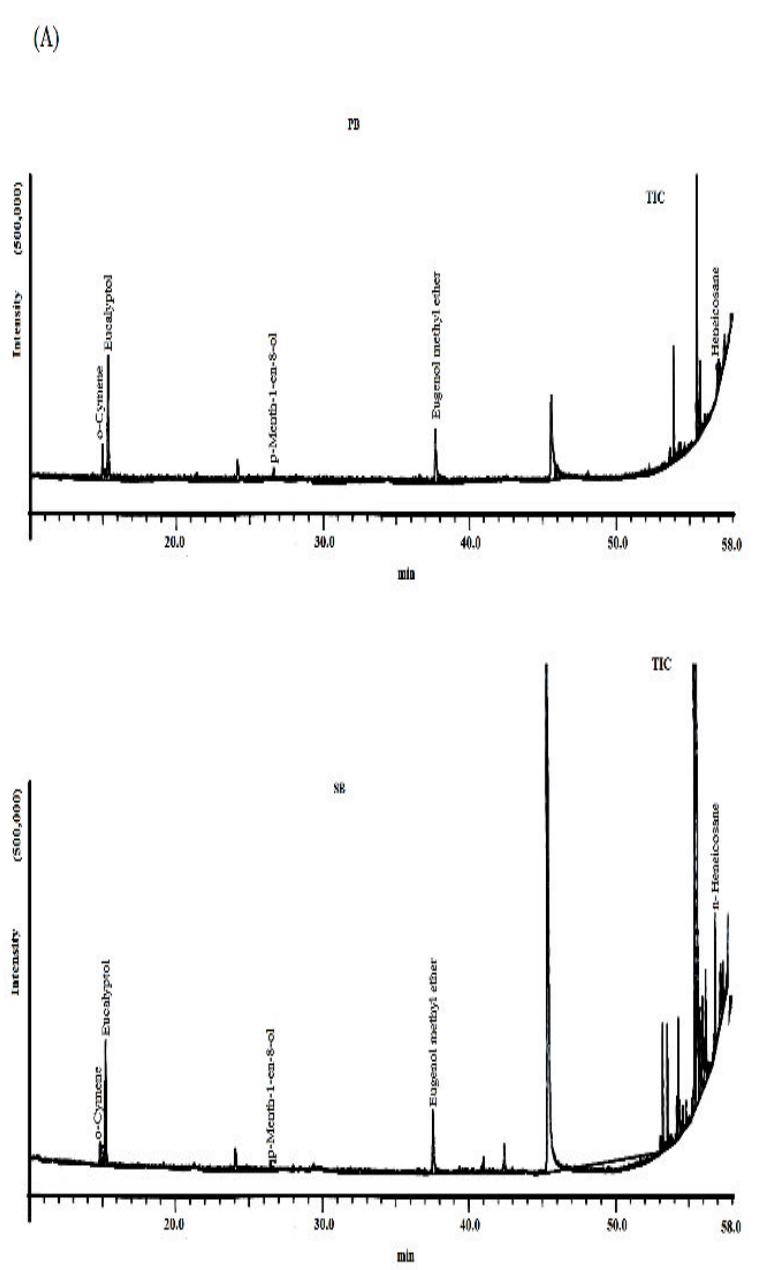

oil was injected into the GC-MS system. Thereafter, it was heated to vaporise and then carried along a column by an inert gas (helium). As the vaporized oil passes through the column, it separates into individual molecular constituents as it interacts with the stationary phase of the column. The separated constituents then pass into the MS followed by ionization and data were full scanned from $60 \mathrm{~m} / \mathrm{z}$ to $600 \mathrm{~m} / \mathrm{z}$. Then, essential oil composition was identified by matching of MS fragmentation with standard spectra in the instrument software. GC-MS chromatograms of extracted essential oils are shown in (Fig. 1).
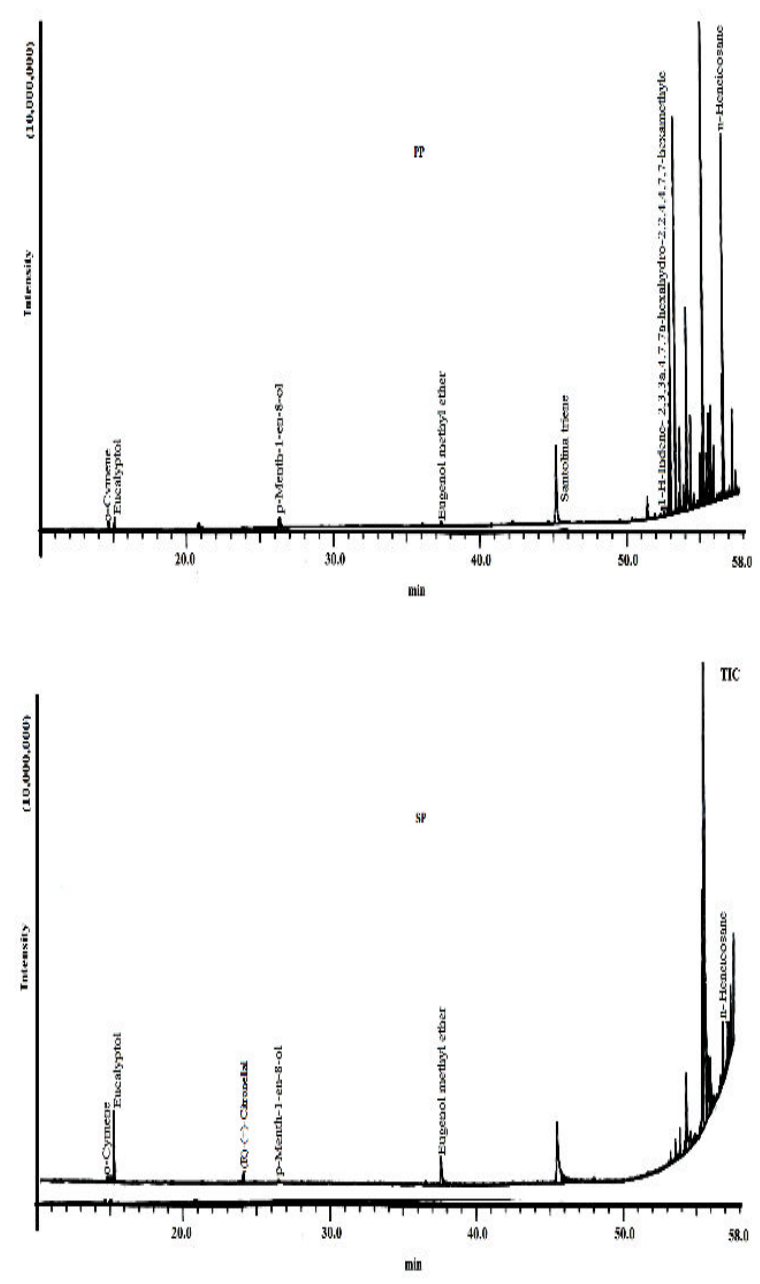

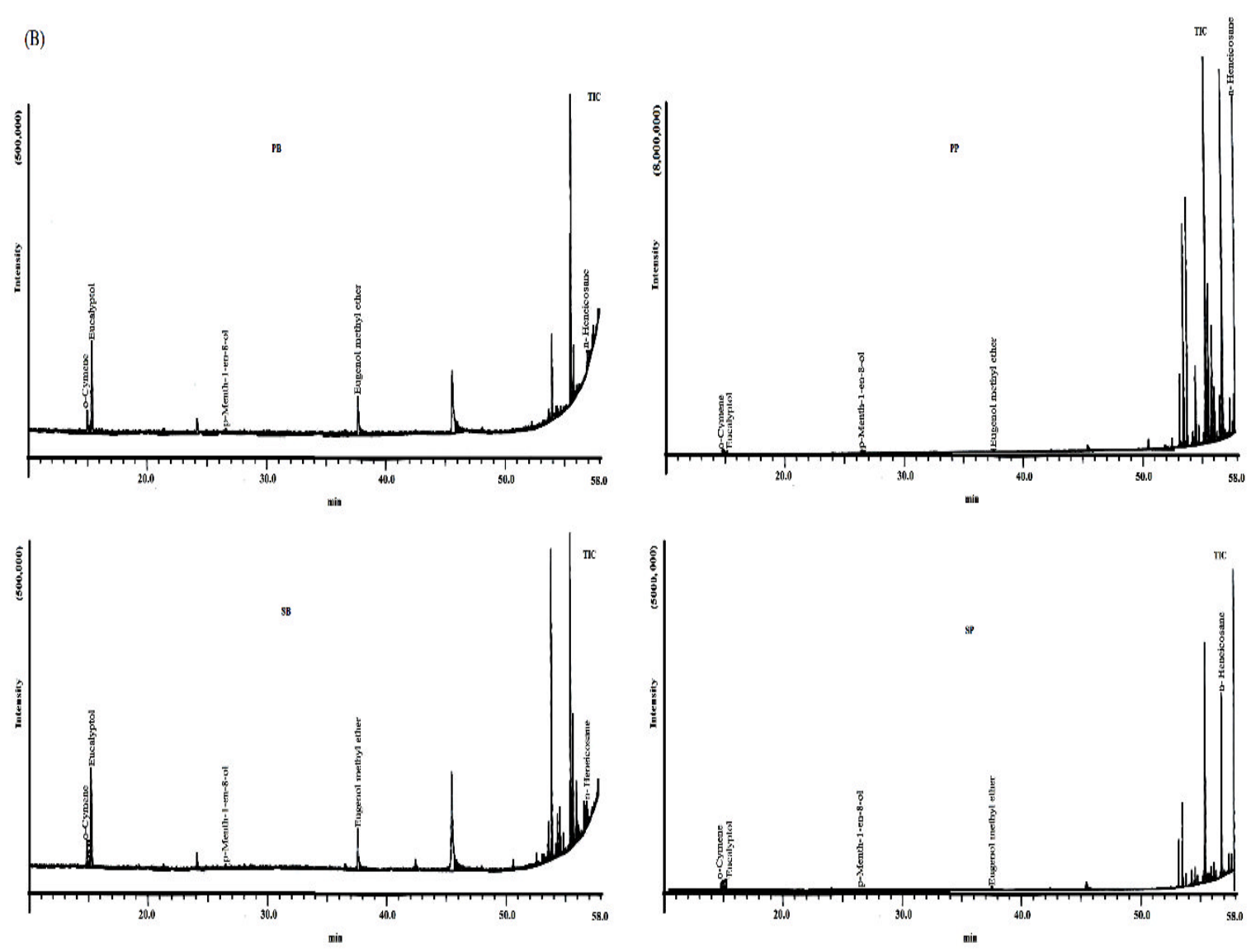

Figure 1. GC-MS chromatogram of extracted essential oil for (A) spring (PB, PP, SB, SP) and (B), winter (PB, PP, SB, SP)

Chemical composition of essential oil collected from different region of KPK, Pakistan

The composition, percent concentration, area of the peak and retention time of each analyzed component is shown in chromatogram (Fig. 2.) produced by GC-MS system and in (Table 2). The chromatogram generated by GC shows the composition of the oil and the rest of the chromatogram that is generated by MS gives the percentage of each analyzed component.

The chemical composition of volatile components analyzed in the essential oil, extracted from rose petals collected from Bannu and Peshawar in spring indicates high concentration of all components in Bannu petals as compared to Peshawar except $n$-Heneicosane. The concentration of $n$-Heneicosane is $91.954 \%$ and $6.238 \%$ in Peshawar and Bannu individually.
Similarly the volatile components in essential oil of Bannu and Peshawar sepals also vary. The concentration of first three and the fifth component (from Bannu) was high as compared to those obtained from Peshawar. While the remaining show high percentile in samples from Peshawar area, in contrast to that the component $(\mathrm{R})-(+)-$ citronellal is totally absent in essential oil obtained from Bannu sepals.

Correspondingly, in winter the volatile components analyzed in rose petals and sepals collected from Bannu show high percentile in all components except $n$-Heneicosane as compared to Peshawar. The concentration of n-Heneicosane is $78.162 \%$ and $93.766 \%$ in sepal and petal of Peshawar whereas their concentration decreases to $3.842 \%$ and $6.238 \%$ in case of Bannu. Few of these components were also determined in Rosa damascene Mill collected from Iran [6, 8, 9]. The 
optimum temperature for essential oil extraction ranges from $20-25{ }^{\circ} \mathrm{C}$. Keeping in view the climatic condition of KPK, Pakistan, it was theoretically estimated that spring season show high essential oil yield as compared to summer and winter because of temperature differences. The comparison is made between experimentally obtained results and theoretical estimation which shows that there doesn't exist a drastic variation between both. As expected, Peshawar being a hotter region show low oil yield as compare to Bannu (having moderate temperature) in spring and winter. Unfortunately no results were obtained from colder region (Chitral) of KPK, Pakistan because of late arrival of spring and longer winter stay in year 2013-2014. Similarly no results were obtained in summer because of too high temperature in the selected regions (of KPK, Pakistan), during summer the temperature of these regions lied between $40-45^{\circ} \mathrm{C}$ which is relatively high from that of optimum range required for essential oil extraction, so undoubtly we could not obtained essential oil during summer.
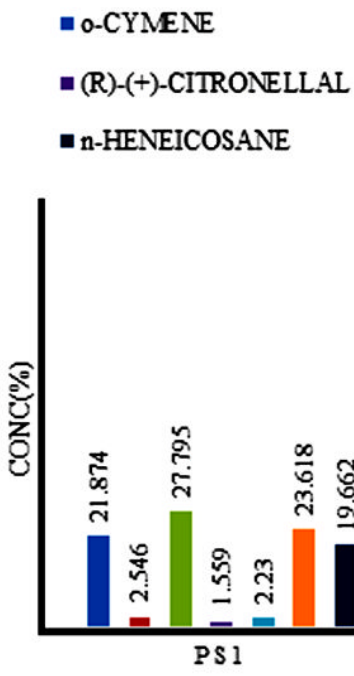

- O-CYMENE

- (R)-(+)-CITRONELLAL - n-HENEICOSANE

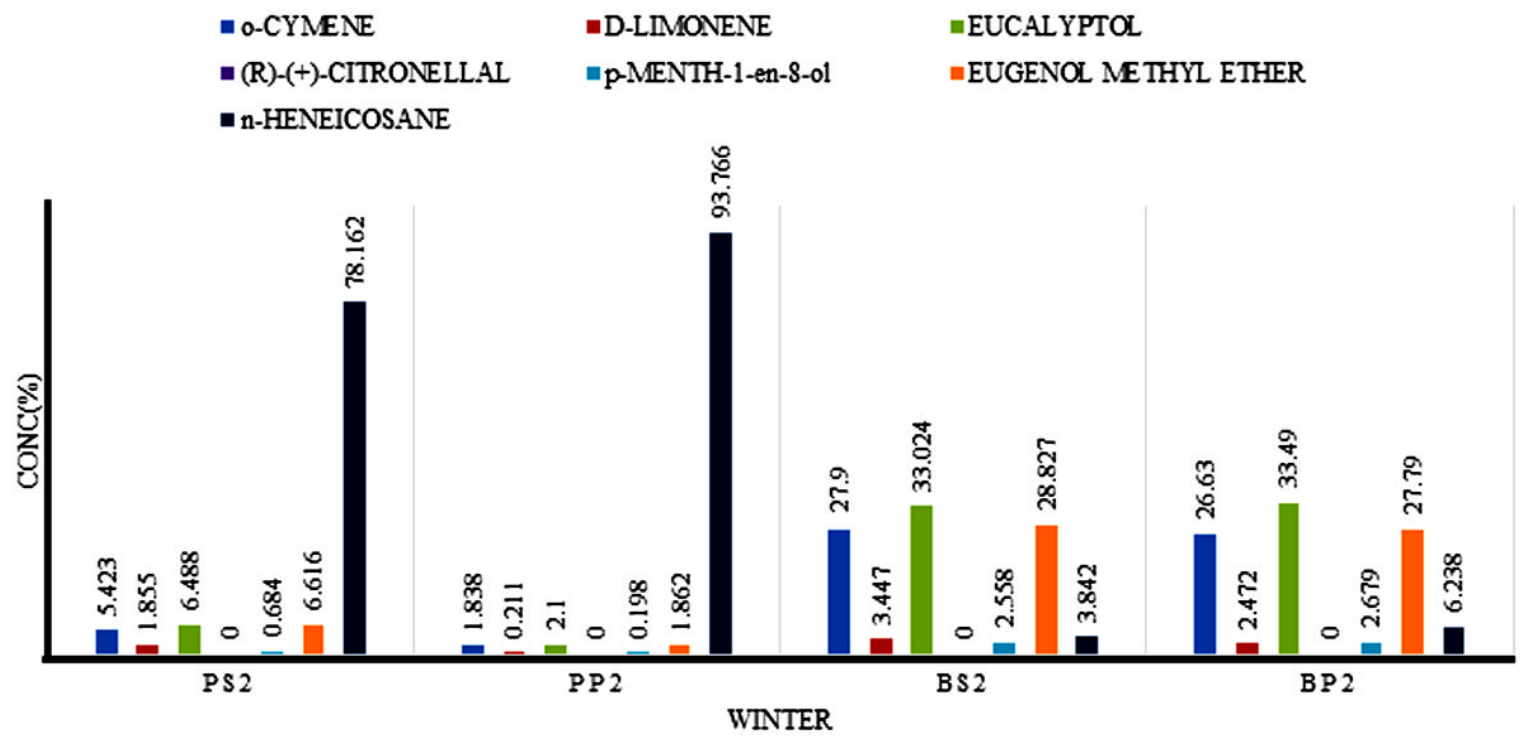

$\because$ EUCALYPTOL

- EUGENOL ME THYL ETHER

Figure 3. Graph showing comparative study of volatile components obtained from spring and winter sampling 


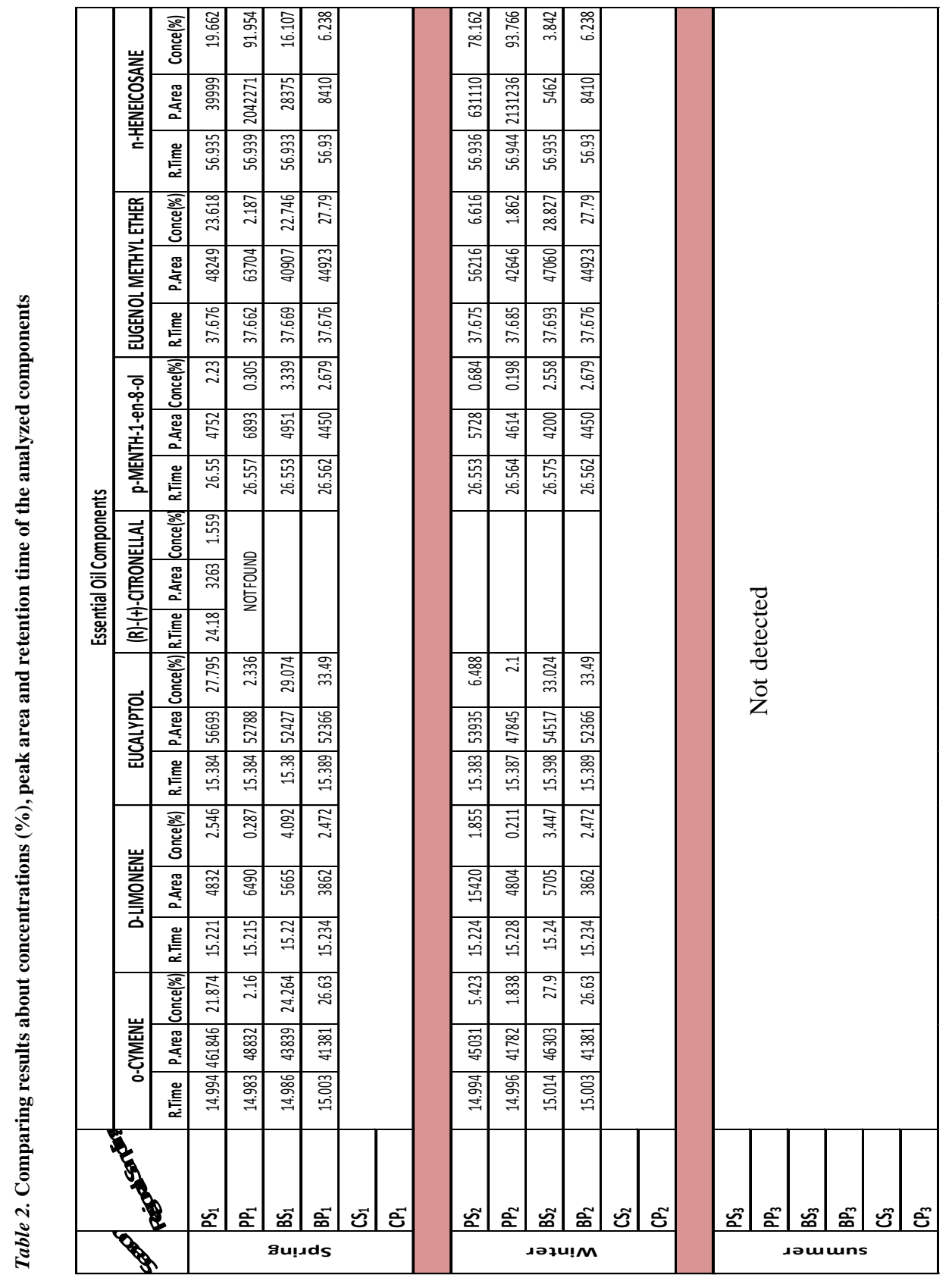

\section{Conclusion}

Rosa Damascena Mill is famous worldwide for its high grade essential oil production mostly consumed in perfumeries. Present study reveals that high yield of essential oil was obtained planted roses in spring season. The Rosa damascena Mill's essential oil was extracted by steam distillation and chemical compositions of these were identified by GC-MS in SIM mode. The obtained results from GC-MS analysis indicate that the Rosa damascena Mill contains several important volatile components i.e. (R)-(+)citronellal, o-cymene, d-limonene, eucalyptol, pmenth-1-en-8-ol, eugenol methyl ether and nheneicosane with extraction yield $3.8 \%$ to $91.9 \%$. The extracted compounds could to be used in perfumery and therapeutic purpose on commercial scale. 


\section{Acknowledgment}

The authors are thankful to HEC Pakistan, for the financial support of this work wide grant No: PD-IPFP/HRD/HEC/2013/1192.

\section{References}

1. E. Derwich, Z. Benziane and R. Taouil, Chem.Bulletin of "Politehnica" University of Timisoara, ROMANIA, 55 (2010) 103. http://chemicalbulletin.ro/admin/articole/418 80art 2(103-106).pdf

2. Saadia Azeem, Azeem Iqbal Khan, Faisal Saeed Awan, Atif Riaz and Sultan Bahadur, Afri. J. Biotechnol., 11 (2012) 10650. DOI:10.5897/AJB10.1375

3. A. Riaz, M. Hameed, AI. Khan, A. Younis, FS. Awan, Pak. J. Agri. Sci., 44 (2007) 2. https://www.ajol.info/index.php/ajb/article/view/9 $\underline{6433}$

4. V Wissemann, Plant Systematics Evolution, 221 (2000) 107. https://doi.org/10.1007/BF01086384

5. $\quad$ S. Gudin, Plant Breeding Reviews, 17 (2000) 159. https://books.google.com.pk/

6. N. G. Baydar, H. Baydar and T. Debener, $J$. Biotechnol., 111 (2004) 263.

https://doi.org/10.1016/j.jbiotec.2004.04.014

7. Loghmani-Khouzani, O. Sabzi Fini and J. Safari, Scientia Iranica, 14 (2007) 316. http://www.sid.ir/En/Journal/ViewPaper.aspx ?FID=95520070405

8. E. Basim and H. Basim, Fitoterapia, 74 (2003) 394. https://doi.org/10.1016/S0367326X(03)00044-3

9. M. A. Khan and S. Rehman, Int. J. Agri. Biol., 6 (2005) 973. http://www.ijab.org

10. Javad Safaei-Ghomi, Sakineh Akhoondi, Hossein Batooli and Mohammad Dackhili, Chem. Natural Compd., 45 (2009) 262. https://doi.org/10.1007/s10600-009-9281-6

11. C. Turek and F.C. Stintzing, Food Res. Int., 46 (2012) 341.

https://doi.org/10.1016/j.foodres.2011.12.028

12. J. Ródenas-Montano, EJ. Carrasco-Correa , M. Beneito-Cambra, G. Ramis-Ramos, JM. Herrero-Martínez, J. Chromatogr. A, 1296 (2013) 157.

https://doi.org/10.1016/j.chroma.2013.04.072
13. H. J. Kim, K. Kim, NS. Kim and DS. Lee, J. Chromatogr. A, $902 \quad$ (2000) 389. https://doi.org/10.1016/S0021-9673(00)00863-3

14. N. G. Baydar and H. Baydar,. Ind. Crops Prod., 41 (2013) 375.

https://doi.org/10.1016/j.indcrop.2012.04.045

15. Bo Li, Chenlu Zhang, Liang Peng, Zongsuo Liang, Xijun Yan, Yonghong Zhu and Yan Liu,. Ind. Crops Prod., 69 (2015) 329. https://doi.org/10.1016/j.indcrop.2015.02.047

16. K. Mac Namara, J. Howell, Y. Huang, A. Jr. Robbat, J. Chromatogr. A, 1164 (2007) 281. doi 10.1016/j.chroma.2007.07.042

17. M. K. Shabbir, R. Nadeem, H. Mukhtar and F. Anwar, Pak. J. Bot., 41 (2009) 615. http://tinkturenpresse.de/doku.php?id=rosa_centif olia

18. M. Özel, F. Göğüş and A. Lewis, Analytica Chimi. Acta, 566 (2006) 172.

https://doi.org/10.1016/j.aca.2006.03.014

19. P. Masango, J.Cleaner Prod., 13 (2005) 833. https://doi.org/10.1016/j.jclepro.2004.02.039

20. Li, D.-x. Kong, and H. Wu, Ind. Crops Prod., 41 (2013) 269.

https://doi.org/10.1016/j.indcrop.2012.04.056

21. M. Ligor, et al., Food Anal. Meth., 7 (2014) 1433.

https://doi.org/10.1007/s12161-013-9767-5

22. Ester R. Chamorro, Silvia N. Zambón, Walter G. Morales, Alfredo F. Sequeira and Gustavo A. Velasco., Nat. Tech University, Argentina, 15, (2012) 307. doi: $10.5772 / 33201$

23. A.C Gören, G. Topçu, G. Bilsel, M. Bilsel, JM. Wilkinson and H. Cavanagh, Natural Prod. Rese., 18, (2004) 189. https://doi.org/10.1080/14786410310001608145

24. J. Meng, J. Tradit. Chin. Med., 34 (2014) 741. https://doi.org/10.1016/S0254-6272(15)30090-X

25. Liu, Chemistry Central J., 8, (2014) 1. https://doi.org/10.1186/1752-153X-8-1

26. M. R. Tellez, J. Chromatogr. A, 1025, (2004) 51. https://doi.org/10.1016/S0021-9673(03)01035-5

27. Fumin Peng, Liangquan Sheng, Baizhan Liu, Hongwu Tong and Shaomin Liu, $J$. Chromatogr., A, $1040 \quad$ (2004) 1. https://doi.org/10.1016/j.chroma.2004.03.057 